International Journal of Child, Youth and Family Studies (2011) 3 \& 4: 432-449

\title{
INTERSECTIONS OF WAR TRAUMA, CULTURE, AND SOCIOANALYSIS IN MENTAL HEALTH INTERVENTION FOR POST-TRAUMATIC STRESS
}

\author{
Athena Madan
}

\begin{abstract}
Refugee war trauma” is a poor adjunct to post-traumatic stress, lacking context for a civilian survivor of war. The "therapeutic mission", or consolidating a therapeutic agenda with political reconstitution, has its tensions: Such founders embody politics of "emotionology" (Humphrey, 2005, p. 205) bound largely to pharmaceuticals, from a land of "freedom" (where emphasis is on market) and "democracy" (where emphasis is on autonomy of choice, not accountability). Additionally, how people "cope" or "solve problems" is not universal: Therapy speaks of self-empowerment, selfactualisation, and self-control; reconciliation speaks of collective citizenship, national participation, and group reform. Instituting participation in rituals that 'help" according to predefined norms of an American prescription to suffering speaks more to the globalisation of the American psyche (Watters, 2010; Venne, 1997) than of humanitarian relief. This paper looks at the absence of cultural and socio-political specificities within the dominant discourse on "war trauma", that are however of ultimate relevance for people affected by war. Using a case example from my own practice with a Rwandan woman living now in Canada, I question the "helpfulness" of post-traumatic stress treatment with this instance of refugee war trauma, and the impact of power systems in mental health care. How can the therapeutic encounter, given its genesis in Eurocentric, patriarchal, enlightenment thought, pause to better consider its potential for injury, especially within contexts of post-colonial genocide? How to avoid a new "mission to civilise"? What tensions to note as the advent of "trauma counselling” seeks more global application and transnational legitimacy?
\end{abstract}

Keywords: medicalisation, mental health, refugee, social world, trauma, genocide, post-traumatic stress disorder (PTSD)

Athena Madan is a PhD candidate in Sociology and Equity Studies at the University of Toronto, 252 Bloor Street West, Toronto ON, M5S1V6. Email: athena.madan@utoronto.ca. 
Traumatology holds particular cultural meanings that can be lost within the contexts of a psychiatric assessment: These may include spiritual and social implications that shape identity, participatory citizenship, and social dreaming. Mental health professionals responding to the distress of post-colonial injury can contribute valuable expertise to communities desiring healing and recovery from trauma; however, contributions should not obliterate local beliefs, customs, and traditions that are relevant to healing.

Bourdieu's notion of socioanalysis considers intersections of individual and institutional forces within social space, and how these qualities shape relationships. Grenfell (2008) defines socioanalysis thus:

Aspirations and expectations, what is reasonable or unreasonable, [what is] likely or unlikely, (and) beliefs about ... actions ... are all conditioned by a mediated form of arbitrary social structure. It is our material conditions of existence that generate our experiences of possibilities and impossibilities ... in turn shap[ing one's] unconscious sense of the possible, probable, and crucially, desireable. The hidden workings of habitus is thus a kind of "socioanalysis", a political form of therapy enabling social agents to understand more fully their place in the social world. (pp. 58-59)

Bourdieu posits that there are cultural, economic, intellectual, psychosocial, political, and spiritual inheritances (referenced as "habitus") which shape a person's way of interacting with the world. Conversely, the world's conditions of governance, economy, and class (referenced as "arbitrary social structure") are also inherited circumstances comprising the ways in which an individual can enact (or not enact) his or her personal agency. Bourdieu was particularly interested in the predictability (Bourdieu \& Wacquant, 1992) with which these conditions shape individual circumstance and capacity for social dreaming.

This article discusses systemic predictabilities of inequity that may manifest in traumatic stress treatment for instances of post-colonial injury. I relate the experiences of Nteza, a former client of mine and child survivor of the Rwandan genocide, now a mother, widow, and landed refugee to Canada via Burundi and the Congo. With reference to Nteza's narrative, I question the "helpfulness" of post-traumatic stress intervention for this instance of refugee war trauma, and reflect on the impact of psychiatry as a power system in mental health care. I argue that the dynamics of mental health treatment shape and are shaped by unchecked political epistemologies; these create PTSD as a dominant geopolitical ideology, and serve to perpetuate injurious and colonial-like personal consequences. As Canada ranks fifth as a target destination for refugee resettlement (United Nations High Commissioner for Refugees [UNHCR], 2011), and as instances of protracted conflict are tragic realities in more than 20\% of the world (Murray \& Lopez, 1996), Canadians need to undertake a more comprehensive understanding about postcolonial and socio-political conflict dynamics in the context of a "helping” relationship, so as to better respond and prevent further injury. 
International Journal of Child, Youth and Family Studies (2011) 3 \& 4: 432-449

\section{Considering Genocide}

Genocide is considered "one of the worst moral crimes of a government", and has resulted in the deaths of approximately 174 million people since the beginning of the 20th century (Canadian Centre for Victims of Torture, 2009). The Convention on the Prevention and Punishment of the Crime of Genocide defines genocide thus:

any of the following acts committed with intent to destroy, in whole or in part, a national, ethnical, racial or religious group, as such:

a. Killing members of the group;

b. Causing serious bodily or mental harm to members of the group;

c. Deliberately inflicting on the group conditions of life calculated to bring about its physical destruction in whole or in part;

d. Imposing measures intended to prevent births within the group;

e. Forcibly transferring children of the group to another group.

(United Nations General Assembly, 1948, article II)

The most extreme documented forms of genocide have occurred in the U.S.S.R. (resulting in 62 million deaths), China (45 million), and Hitler's Germany (6 million). Since World War II, documented genocides have also occurred in Tibet, Guatemala, Guinea, PakistanBangladesh, Cambodia, East Timor, Burundi, and Ethiopia. The last quarter century has borne witness to and prosecuted Darfur, Rwanda, Sudan, and the former Yugoslavia. Areas under concern or at risk of genocide in the last 25 years (Office of the Special Advisor on the Prevention of Genocide, 2011) include occupied Afghanistan, the Democratic Republic of the Congo (DCR), Iran, Iraq, Israel, the West Bank/Gaza Strip, Somalia, and Sri Lanka. The 1994 genocide not only decimated Rwanda, but sparked tensions in Burundi, the DCR, Tanzania, and Uganda. From UNHCR estimates, not including the voluntary repatriation of displaced persons, the 1994 genocide still affects 5.8 million refugees worldwide (United Nations, 2009, and my own extrapolations). The point being: The 100-day war has resulted in consequences as significant and as long-lasting as the Holocaust.

I reference these facts to illustrate that genocide-affected migrants are not an isolated minority; indeed, the World Health Organization and the World Bank predict that war will be the eighth leading cause of death and disability by 2020 (Murray \& Lopez, 1996). It is thus likely that increasing numbers of patients will present with lived experiences of war as part and parcel of their medical and psychological histories. But particularities of genocide and mass violence are complex, each carrying contexts and consequences that are not yet documented or fully understood. Indeed, a recent Canadian study with psychiatric resident students reported that, although most residents had encountered a patient who had been traumatised by war, none reported feeling completely prepared, and that 90\% desired to learn more about this area (Munshi, Woods, \& Hodges, 2010). Further, the above naming of conflict is not definitive: Advocates, lawyers, and political scientists all suggest that declaring or discerning the Convention's “intent to destroy" clause is precarious, outside the scope of Autonomy's rule (see (Kupchan \& Mount, 2009), and fraught with both political and politicised interpretations. 
International Journal of Child, Youth and Family Studies (2011) 3 \& 4: 432-449

It is important to note that genocide is a distinct form of mass violence in two ways. First, when the United Nations declares genocide - a process that some argue has in itself also become political (to review, see Moses, 2006) - the international community is required to intervene, as mandated by the 1951 Convention; however, as the U.N. has yet to agree on exact parameters of intervention, political and humanitarian intervention efforts often present with conflicting agendas of interest, and are in direct competition for resources to deploy aid. Second, also according to the 1951 Convention, acts of genocide (since 1951) are punishable by international law. This may affect whatever stability of immigration protection and intervention a host society may be able to provide. Analysis of decisions concerning the Convention's implementation, and the U.N.’s governing enactment of it, are outside the scope of this article.

\section{Genocide and mental health}

The author has previously discussed (Madan, 2010b, p. 262) mass organised violence such as genocide as having “deep, systemic, and ingrained long-term implications”: as conflicts are so protracted, trauma includes an ingrained political reference to collective identity and postcolonial tension, with a collective experience of subjugation that translates into a feeling of "being less than human” (see also Madibbo, 2005, p. 13). Very relevant in the aftermath of mass organised violence is a heightened sense of collective loss: Community, dignity, family, property, safety, and interpersonal rights have all been stripped, with direct experience or witnessing of indiscriminate mass killing, open systematic rape, and torture. With regard to children, the consequences of genocide also include a schema where violence is accepted, acceptable, and expected, and that murder is legislated power (Beah, 2007).

The refugee experience (fleeing the conflict) lends additional complexities. Blackwell (2003, 2005) and the World Health Organization [WHO] (2004) note these may include a loss of culture, home, and status, with fear of perpetuating losses under threat of deportation. This threat of deportation creates an adversarial relationship with a government the refugees are still trying to trust; moreover, stress from daily circumstances often includes inadequate housing, a poor diet, financial instability, and separation from or the death of family and communities of origin. Specific to relocating children, Revell (2001) and the National Institute of Mental Health [NIMH] (2002) note that there can also be fears due to the following: the unavailability, disappearance, or death of family members; interruptions to schooling; difficulties with a potentially new language; and a general, sustained sense of uncertainty.

Additional points to consider in war trauma pertaining to diaspora include a legacy of feeling perpetually second-rate (Canadian Broadcasting Corporation [CBC], 2009; Shamsuddin, 2009), a collectivist world view, and a response and ability to act in the commemoration of loss (or, as is said in the case of the Rwandan genocide, "le devoir de mémoire"). Thus, while the diagnostic framework and reasons for referral in the case of war trauma may focus on a set of particular behaviours in a particular individual, there are a myriad of external, social factors that serve as very relevant points of analysis. To ignore the impact of these has potential to perpetuate stress, instead of alleviating it or building resilience in resettlement (McLellan, 1995; Yohani, 2010). 
International Journal of Child, Youth and Family Studies (2011) 3 \& 4: 432-449

\section{Current psychiatric approaches in intervention for genocide and mass organised violence}

Current practice for trauma from genocide rests on diagnosis and treatment for posttraumatic stress disorder or PTSD (American Psychiatric Association [APA], 1994), mainly because PTSD comprises the diagnostic language that's available. Theoretical, clinical, and empirical support for various therapies in the treatment of PTSD is still emerging. While some alternative modalities have been seen to yield moderate "results" in positive treatment outcome, pharmaceutical and psychological modalities remain the ultimate focus of this article.

Increasing numbers of genocide-affected migrants are being referred to institutions for PTSD treatment (Canadian Centre for Victims of Torture, 2009), but the effectiveness of services seems to be poor. The dropout rate or loss of participation in follow-up is high, and for many clients, distress that presented at referral is still just as present upon termination. Poor engagement and outcome of PTSD treatment may reflect the following procedural deficiencies: an understanding of cultural responses to distress (Snider et al., 2004); an understanding of resilience across different cultures (Bhui, McKenzie, \& Gill, 2004; Summerfield, 2008); individual support or political will to sustain participation in therapy (Simich, 2010; Summerfield, 1998); or, refugees feeling entitled to talk about or evaluate their experience as clients (Vasilevska, Madan, \& Simich, 2010).

Gaps also exist in current psychiatric practise about negotiating diasporas as a result of genocide and mass organised violence: Political tension, collectively sustained violence, or the immigration experience beyond settlement have little terms of reference in diagnosis; AngloAmerican and psychiatric interpretations dominate interpretation of symptoms; and "immigrant and refugee” contexts are undifferentiated in psychiatric literature, with generalised interpretations of war, and assumptions that traumas are carried throughout the migration process unchanged. Further, absent are clinical guidelines (or assessments) specific to genocide's emotional effects, or considerations within which "healing” and "social change" for refugees are relevant (Bracken, Giller, \& Summerfield, 1995; Summerfield, 1999, 2001b).

\section{Cultural relevance of PTSD in instances of war}

Summerfield (2001a) has noted points of traditional psychotherapy that exacerbate postcolonial injury: its genesis in western European enlightenment and patriarchal thought; a focus on the individual as the root of pathology; and a process of assessment that lacks multicultural norms. To not consider these nuances, or consider them as attenuating, independent, or nonprimary factors, limits the "success" of any eventual outcome (Summerfield, 1995; Bhui et al., 2004; Blackwell, 2005).

So as the practise of "trauma counselling" seeks more global application, it important to pause and consider how this new enterprise grounds itself as culturally appropriate. Of their work in Peru with survivors of political violence, Snider et al. (2004) write:

Some of the dangers of indiscriminate application of Western schema, such as "PTSD" to indigenous societies include: (1) pathologizing normal responses to stress, (2) lack of attention to cultural bereavement and socioeconomic context, (3) bias towards 
International Journal of Child, Youth and Family Studies (2011) 3 \& 4: 432-449

individualist treatment approaches stigmatizing to local persons, (4) "category fallacy”, or the false idea that symptoms described in different contexts share the same meaning, and (5) reductionism of the meaning of traumatic experience into clinical descriptors. The meaning people ascribe to traumatic events, to their losses and to their survival of those events, has powerful implications for recovery. (p. 390)

There a need to better understand the impacts of mass trauma on communities, but mental health professionals must also recognise the limitations of psychiatric concepts and approaches in attempting to capture the full meaning of traumatic events to their communities. Interventions need to be designed appropriately to recognise the complex realities of a group, including attachments, networks, interrelationships, and experiences. There is growing awareness of the relevance of ethnocultural group influences in therapy; however, many assessment processes and treatment models are slow to incorporate independent, multicultural norms. Snider et al. continue:

As Western-trained mental health professionals tend to focus on clinical psychiatric problems alone [in treating contexts of war], the cross-cultural validity and context relevance of their approaches have been called into question. The expression, recognition and treatment of mental disorders are rooted in culture and social context. Psychiatric diagnostic schemes and treatment approaches reflect an individualist context that may be inappropriate for collectivist societies ... political conflict is imbued with unique meaning for the communities involved. For these communities, trauma may be felt as a collective experience, and psychosocial recovery of individual members related to restoration of the community's cultural and social traditions. As some experts argue, when the wounds of war are communal, approaches to healing should also be communal. (p. 390)

Current psychiatric ways of "knowing” are limited to a Eurocentric, patriarchal, enlightenment thought; and while science can translate invariably across contexts, how people "cope" or "solve problems" is not universal. While those designing intervention for psychological relief may have genuine intent, care should be taken to note ways in which intervention is actually desired. If treatment or intervention has limited community or cultural relevance, consequences may foment additional symbolic or territorial atrocities. The Center on Law \& Globalization (2011) writes:

All genocides are different. However, four ideologies commonly preoccupy perpetrators of genocide: racial and ethnoreligious hatred, cults of antiquity, cults of agriculture and territorial expansion. These ideologies serve to both foment and justify genocidal atrocities. When we see these ideologies being touted, we should keep in mind that genocide has sometimes waited in their shadow. (p. 1)

It may thus be that instituting participation in rituals "to help" according to predefined norms of an American prescription to suffering speaks more to the globalisation of the American psyche (Watters, 2010; Venne, 1997) than of humanitarian relief. Because the genocidal context has as its root an ideology of superiority and dominance, the psychiatric encounter would do well to re-evaluate how it aligns and positions its expertise. To not do so embodies a sort of "going 
International Journal of Child, Youth and Family Studies (2011) 3 \& 4: 432-449

boldly where few psychologists or social workers have gone before” (see Madan, 2010a); this risks repeating the colonial encounter.

\section{Nteza: A case study}

"Nteza” means “I’m expecting” in Kinyarwanda, the central Bantu (people’s) language of Rwanda, Burundi, and northeast DCR. While I have chosen this name to represent her in sharing her narrative, I have tried to preserve the rest of her words and experience with as much integrity as possible. For this reason, and also to capture the beauty of her speech, I include Nteza's French expression first, before translating them into an English equivalent; she adhered to a formal, respectful form of address with me, and frequently employed symbolic and metaphorical expressions as vehicles of emotional meaning and expression.

Nteza was a 27-year-old Tutsi Rwandaise woman who came to Canada as a refugee via the Congo. She was referred to me by a colleague, her nurse, who felt she could benefit from emotional support through her pregnancy. Nteza had been diagnosed with war-induced PTSD by a previous medical practitioner. The nurse told me that during her first appointment, Nteza started crying in her office when she told Nteza the baby was a boy. Nteza had been in Canada for four months, and was almost six months pregnant. She also had a 4-year-old daughter.

Nteza was at first hesitant to discuss her pregnancy with somebody new, but her nurse introduced me as "une amie sur son équipe / a friend on her team". I elaborated that the nurse had told me a bit about her situation, about being a refugee in Canada; that I was there to help, that I was there to talk about "internal sorrows". I told her I understood her pregnancy was the result of having been raped in the Congo, that her husband was in prison for political reasons, and that hers must be a very difficult emotional load to carry. I wondered aloud that perhaps she did not have to carry that load herself; and I assumed that talking about her load might be helpful.

Nteza smiled very shyly, and responded, with eyes downcast, that life carried with it new dreams here; that the "devoir de mémoire, ici, n'est pas pareil / the duty to remember and honour ancestors, here, is not the same ${ }^{1 \text { ". }}$. She said she missed her family: Her mother and

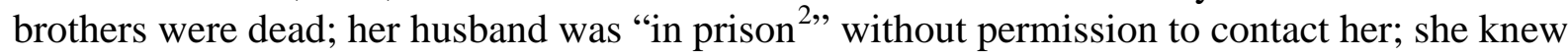
nothing of any friends or community. She had fled Rwanda at 13 with an uncle, Uganda at 18 with a family friend, and the Congo at 26 with her daughter - each instance of flight had been due to brutal circumstances of war and exclusion.

Nteza's social support in Canada was small, but considerable: She had started involvement with a church group, shared a house with her pastor, and had recently befriended a neighbour from Haiti who had a daughter the same age as her own. However, she said that the

1 "The duty to remember [and honour ancestors], here, is not the same" (trans.). "Le devoir de mémoire" is a Rwandan phrase of commemoration specific to the 800,000 killed in the 100-day genocide, not unlike "Lest we forget" marks Remembrance Day and the remembrance of WWI and WWII veterans and fallen soldiers in Canada, the United Kingdom, Australia, and New Zealand.

${ }^{2}$ Often, euphemism for death by unnatural circumstances. I suspect that being a widow, and a victim of rape, were not favourable considerations of status in Nteza's communities of origin. These ramifications, or these considerations, I did not discuss. 
pregnancy was difficult, both in physical and emotional weight and impact. Her biggest loss was not having community during this time of preparation.

Nteza reflected that she struggled most with feelings of conflict. She felt anger and regret at having discovered abortion would have been an option just four weeks ago; torment that she would have considered such a "discretion non-humaine / inhuman act of will"; and sick that she was at present carrying, and preparing to care for, the seed of hate. The idea of adopting seemed equally horrendous as it was welcoming. She was surprised that the Canadian system didn't have orphanages, and learned about foster parents with an air of fascination and curiosity. She was also worried about how to explain the potential loss of a sibling to her 4-year-old daughter, who expressed interest and curiosity about being a big sister. In the end, Nteza decided to keep the baby.

Nteza came regularly to therapy throughout the pregnancy. She liked Beethoven; she dreamed of playing the piano; she loved to walk alongside the Canal, saying she would watch and listen in silence and find "peacefulness" as its clear-ish waters flowed. She always spoke shyly and with eyes downcast, and I became very familiar with her shy, private smile. She unfailingly kept appointments, reliably navigating herself, her visibly heavy belly, and her daughter on the hour-long bus ride without complaint. When either I or my colleagues had to cancel our home visits, due to some pressing or unplanned consideration at the clinic, she would always say, "D’accord. Je vous accueillirai prochainement. / Okay. I will see you then next time”. Her humility touched me. I reflected that perhaps I was not the most ideal source of support for Nteza: I was a stranger in a strange land; my privilege cast me as unable to identify, really, with her struggles on a day-to-day basis; and however likeable our rapport, I was more like a sister than an elder helper. The constructs of my office, with all its care about "confidentiality" and "professionalism”, offered no pride to her. But I recognised that I was, despite all of these things, a woman; that was enough to give me privileged access.

Two weeks after the birth, Nteza's nurse and a visitation worker contacted me after a home visit, concerned about the level of despondency they had observed. Nteza " $n$ 'était pas dans la zone / seemed out of it" while breastfeeding, with demonstrated difficulty in responding to the infant's cries; they also reported her energy level and affect seemed very low overall. I had noted Nteza seemed withdrawn the last time that I had seen her; I shared with the nurse that she had expressed feeling overwhelmed with caring for the child, about whom she had felt ambivalent even carrying. The visitation worker shared that the infant was noticeably underweight, and that she was concerned about the lack of attachment between Nteza and the baby. Nteza had also not yet chosen a name.

The nurse scheduled an in-clinic follow-up for Nteza and the children, and during this appointment felt Nteza was "so symptomatic" that she was concerned. The nurse called me into her office to speak with Nteza. Nteza said her stress was "au point que j'ai besoin de quitter . . . je ne partirai jamais, mais la paix de la fleuve. . . j'aimerais flotter loin d'ici, loin de ces difficultés / to the point where I need to get out ... I would never leave, but the river's peacefulness ... it would be nice to float away, far from here, far from these hardships”. I tried to translate to the nurse that Nteza had always found the river peaceful, in fact liked to take walks and meditate there; but it was decided this was of sufficient concern to necessitate intervention. 
International Journal of Child, Youth and Family Studies (2011) 3 \& 4: 432-449

The nurse referred Nteza for psychiatric emergency evaluation for post-partum depression, citing a suicidal plan with access.

Mental health policy has a way of defining procedures, for the purposes of clarity in crisis; unfortunately, they do not always translate well or effectively to the situation at hand. Systemic regulations, while designed for prevention and crisis management, in fact only served to bring up new crises. Nteza's symptomology, and specificity of her "plan”, qualified medically as "severe". She was referred for emergency psychiatric evaluation; this necessitated transport in an ambulance to the emergency ward; this in turn necessitated foster care placement for her children whilst there. I was given charge to explain the intervention system to Nteza: why the ambulance was being called, why child protection was being involved, links between posttraumatic stress and feelings of sadness or stress; I also thought I might maybe explain a little bit about what "hospitals here" looked like, and what relief we thought a "post-partum depression diagnosis" could bring.

Even though agencies are not required to offer such explanations, and ill-equipped to have the time or resources sufficient to do so, to this day I cannot say there was any "humanity" in this task. Nteza expressed repeatedly not understanding why she didn't have a choice to go to the hospital, why her children and I couldn't go with her, and that she did not want to be diagnosed as depressed. I could only offer lame responses of "C'est la loi / It's the law" about the ambulance, "Tu nous inquiètes / We're worried about you” about the depression, and "Vos enfants seront corrects / Your children will be okay” about being placed. I asked for my supervisor's approval to negotiate being able to meet Nteza at the hospital emergency room; with Nteza, I suggested to child protection arranging foster placement that the children please be placed under the care of her pastor. In both instances I was told my recommendations would be considered, but that these were things that ultimately the respective agencies now involved would decide. It was then that the ambulance driver arrived to bring Nteza on board. Nteza looked at me and said, “Ceci ne va pas m'aider / This is not going to help me”. As the ambulance personnel carried her away, I could hear her crying out for her mother.

Nteza was already admitted when I reached the hospital; triage personnel said that they didn't have consent for me to accompany her admission, even if they could tell me what room she was in. Three days later, we were informed Nteza had been admitted under suicide watch and released 17 hours later, during which time she received a diagnosis of post-partum depression and one sample of an anti-depressant. The brief noted that she had been non-compliant to treatment. Child protection services united Nteza with the children after she was released, though they continued to monitor her regularly for some months after about "parenting”. Nteza never returned, either to our clinic or the hospital, for services.

\section{Advocating for psychological debriefing on a systemic level}

These events have been ones that I have deconstructed for some time, in efforts to discern what could have been done differently - I'm not convinced that our intervention was successful. In fact, I think our actions were quite disastrous. While these events were extreme, Nteza's experience illustrates how PTSD intervention lacked relevance to her circumstances, compounding the impact of what had already happened. This section addresses my personal 
reflections about Nteza's experiences - perhaps the only way her story may be heard by this audience - and how I have since understood what created such unintended inequity. PTSD intervention lacked socio-political context for Nteza's circumstances in the following ways:

1. Variable perceptions of trauma. In psychiatric discourse, it is a physiological and psychological injury; according to Rwandan consciousness (for review, see Bagilishya, 2000), it is considered as a spiritual trial, and a disruption to the social or collective order. Nteza perceived her "symptoms" differently, and felt they were more spiritual in nature than mental or physiological. She expressed herself as such. But the symptomatic checklist, or "what we know about trauma", overrode her perceptions as being secondary in nature.

Present systemic interventions suppose and impose reactions of trauma, according to normalised contexts from a high-income world view. Nteza's treatment was arranged and measured according to our own formulated prescriptions; we assumed our actions were "correct", in all our administrative and governing authority. However Nteza, even in her moment of crisis, displayed visible expressions of affect, verbal articulation for what she perceived were her stressors, and a coherent organisation of thought about what was going on around her. If symptomology defined our categorisation of her, then these symptomologies were neither depression nor PTSD.

I have also since reflected that Nteza's treatment was more about the system, and about Canadian life, than Nteza and her children. The team's decisions based on "worry" and interpretations of behaviour were curiously absent of her own points of reference while Nteza recognised she had sadnesses, and sometimes doubts about desire for "a new motherhood”, her feelings were acknowledged and contextualised appropriately for her particular circumstance. Further, her desire to not talk about traumas in chronological order, despite her articulate ability to recall emotional and physical detail, was considered in her initial medical examination ${ }^{3}$ to be a "maladaptive coping mechanism" and a point of significant pathology. I note Summerfield's (1998) observations that surviving genocide may "indeed mean a life sentence, but this is not necessarily a trauma” (p. 1249).

2. Political frames of reference. Trauma intervention initiatives in Rwanda are seen to be implemented on a group level, using groups and families to support individual

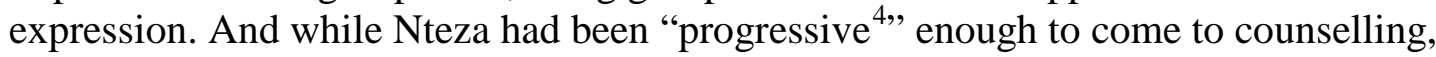
what she ultimately desired from services for her and her children was room to exercise strength, not personal instability. She was carrying her sadnesses with dignity, as her own

\footnotetext{
3 The psychiatric context advocates a chronological ordering of traumatic incidence, neatly sequenced from beginning to end. Disruptions or an incoherent narrative reflects a still-traumatised state of mind.

4 "Progressive", as counselling is still puzzling to Rwandans: Circles of support to deal with sadness or distress naturally include family and community members; distress is largely discussed indirectly; it is further inappropriate to discuss intimate inner details with, display emotion to, or ask for help of someone who is not immediate family. Trauma counselling initiatives in Rwanda thus incorporate particular modalities emphasising group format (instead of individual therapy); metaphorical or symbolic storytelling (as opposed to "establishing the chronological narrative of traumatic fact"); visual or musical expression as primary modes of treatment (instead of being adjunct or allied therapies); and building bridges for advocacy with community leaders (instead of "remaining neutral”). Interestingly, these initiatives are largely considered as "soft intervention techniques" to funding agencies and companies; they can frequently only find support as project-driven initiatives, not sustainable operations.
} 
International Journal of Child, Youth and Family Studies (2011) 3 \& 4: 432-449

cultural context prescribed.

I have since reflected that Nteza deserved better advocacy for her personal agency. "Dedicated will” (Dallaire, 2003, p. 520), aside from being one of the few key identifiers of self left after a genocidal context, embodies a highly politicised and resistant attachment to an oppressive regime: agency, equity, and access (if not justice) become significant components to healing, well-being, and survival. Any medical treatment for her "sadness" could have had better dialogue and more understanding contexts, so as to foster strength in her own time, and in the language of her own resiliencies.

3. Cultural frames of reference. These were especially relevant for rituals surrounding birth, life, and death. Considering ancestors as living protectors, Nteza revered her deceased family and community members with a special status. It was considered appropriate for her to call upon them for spiritual strength in moments of fear or pain. Had this construct been known, emergency dispatch personnel would have understood Nteza's calling out for her mother as she was being sent to the ambulance - it was not a sign of psychosis, but a natural expression of fear, grief, or assistance for her children. As it was, her calling out added another check on the symptomology checklist necessitating emergency psychiatric intervention.

Additional cultural complexity surrounds traumatic loss in Rwanda: circumstances such as war which prevent proper mourning, burial, or even care for the dead are legitimate cause for great distress. Nteza's ancestors - her mother, grandmother, brothers, and husband - had not had proper initiation to their new world, requiring a heightened “duty to remember / devoir de mémoire”. Thus, for Nteza, for whom “[u]nder these circumstances, the mourning period offers no solace” (Bagilishya, 2000, pp. 346347), her sadnesses were spiritual pains; they were her rightful burden to carry (and call out for) until her ancestors could find relief.

4. Spirituality. The contexts of collective mass violence added complexity to Nteza's pregnancy: Sexual relations are forbidden during the mourning period. A child conceived so soon after death is considered merciless, or at the very least shameful to the family; even if born of rape, both mother and child are subject to expulsion by the head of the family. Bagilishya (2000) writes of a Rwandan proverb which suggests that "[E]ven the earth must stop producing ... so it is strictly forbidden to cultivate and to sow” (p. 346) during time of mourning. A pregnancy that disrupts the mourning period is considered unclean, unworthy of communion on earth (home of community) or in sky (home of ancestors). This adds some clarity to Nteza's attachment to the Canal, and it was not a design of suicidal access: Water was the only appropriate element that could sustain her spirituality.

5. Reciprocity. The "way our system works" - PTSD's disciplinary power - leaves no emphasis for dialogue, exchange, or consideration of alternate context. At least, in my own position I felt too powerless (or perhaps too docile) to suggest "tout

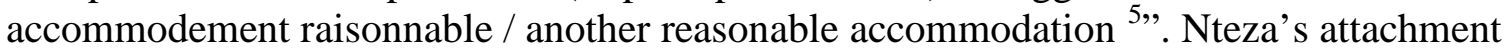

\footnotetext{
5 "Reasonable accommodation" (trans.): Canadian legislation (first initiated in 1985) addressing fairness and equity in the workplace, regardless of physical ability and religious or cultural affiliation. It is currently a hot topic of debate within Québec, especially as these diversities intersect Quebec's historical advocacies of
} 
International Journal of Child, Youth and Family Studies (2011) 3 \& 4: 432-449

to her ancestors, her communion with the river, her beliefs in community, and her intent in seeking help - none of these could be translated across departments or advocated for appropriately. The very framework of the mental health system predetermined Nteza's participation as a client: It set her up for alienation and failure. Further, the "task" in explaining the systems and regulations in Canada to Nteza as a newcomer (which in itself assumes a certain lack of historical non-existence), coupled with difference of word and of language (see Bhugra \& McKenzie, 2010; Bouchard \& Leis, 2008), seems an ill-timed and unfortunate preoccupation with bureaucracy. I have since reflected that Nteza fled one autocratic rule in life, only to be replaced by another one - and even though judgement included neither height nor the shape of her nose, we may have been just as equally unforgiving.

"Medical experience now has a collective subject" (Foucault, 2003, p. 35), but how to define the parameters of this new collectivity? Can those who have the power to name them be indulged to do so? What could make new parameters possible? Present therapeutic encounter is shaped out of a particular gaze (Foucault, 2003), a gaze with the power to exclude and repress, and with functions sustaining current, "political device[s]" of psychosocial control (Moncrieff, 2010, p. 370).

Nteza's experience has furthered a questioning to more extended implications. Current, prescribed treatment for PTSD assumes one way of healing - how to give legitimacy to others? If impairment of attachment requires healing in attachment (Bowlby, 1977), what does this mean for injurious post-colonial relationships? What could new relationships look like? How does one reconstruct associations - cognitively, emotionally, physically, and spiritually - that have become ecological, embodied, and symbolic forms of "knowing", and of "being", and of "remembering"? Further, how are associations reconstructed while meanings have impacted a collective, and may have shifted - across spheres of circumstance (Bourdieu \& Wacquant, 1992; Foucault, 1972), across geographical boundaries, and across time?

\section{Healing and transformation}

The import of psychiatric knowledge as expert witness ("war trauma equals symptom $x$ and phenomenon $y$ ") is problematic: It imposes a new hierarchy of superiority, where understanding is an act qualified through authority, with canon-like control of the "magic" of healing. There is also an ideological divide in applying psychiatry to low-income contexts, in that therapy can be seen as a manufactured economy funded by companies whose interests are vested in being ill. In addition, local politics have created massive global inequities of socioeconomic power. The "therapeutic mission", or consolidating a therapeutic agenda with political reconstitution, further has its tensions: Such founders embody politics of "emotionology" (Humphrey, 2005, p. 205) bound largely to pharmaceuticals, from a land of "freedom" (where emphasis is on the market) and "democracy" (where emphasis is on autonomy of choice, not accountability). Intervening without recognition of such divergent position in relationship is an "act of absorption” (Short, 2005, p. 273), reifying already dominating

protectionist policy for the preservation of its own language and culture. See

http://fr.wikipedia.org/wiki/Accommodement_raisonnable (last retrieved December 19, 2010). 
International Journal of Child, Youth and Family Studies (2011) 3 \& 4: 432-449

structures of power. It could be that the "right" to treatment is "a social process, involving power, and should be analysed as such and not assumed to be beneficial” (Short, 2005, p. 276).

Pharmaceuticals, and counselling and psychotherapy disciplines - the political and economic bodies representing powers governing PTSD - are "[bound] together ... by insidious extension" for "the internal rule of maximum economy ... and the raison d'État" (Foucault, 1979, 1995). The No-Nonsense Guide to World Poverty further addresses the need for caution with regard to international intervention:

To extinguish alternatives [in intervention] is as intolerant as it is violent. Globalisation is ideology made material: ideology not as theory but in relentless, inflexible practise. To say: "There is no market for it" - whether "it" means some commodity or service, or whether it means compassion, wisdom, self-sacrifice or some form of expression - is to condemn areas of vital human experience to silence and non-existence. (Seabrook, 2003)

Bourdieu similarly looks at the role of economy as material barrier to conscious and creative change. He writes:

The task is to produce, if not a "new person", then at least a "new gaze”, a sociological eye. And this cannot be done without a genuine conversation ... a mental revolution, a transformation of one's whole vision of the social world. This new sociological "gaze" is underpinned by a relational mode of thought. (Bourdieu \& Wacquant, 1992, p. 251, emphasis added)

That PTSD is an export to low-income contexts and discourse (Summerfield, 2001b; Favila \& Fellow, 2009) does not necessitate unequal distribution in the field where intervention takes place. However, from a high-income world view, the developing world's adversities have become marketable. In some circumstances, they are consumable for episodes of spectacle, entertainment, and commodified loss; in other circumstances, they are props for selfcongratulatory, fashionable, and token gestures of generosity. Within the high-income context, therapy speaks of self-empowerment, self-actualisation, and self-control; indigenous community initiatives tend to speak to collective citizenship, national participation, and group reform. Trauma in many low-income contexts signifies a collective and spiritual meaning, with considerations of coping legitimised very differently. Given the literal capital that high-income contexts carry, this binary is important to recognise before (re)assessing the sociological gaze.

\section{Conclusion: “There, they kill you with bombs. Here, they hurt you with feelings” 6}

Within the contexts of genocide and mass organised violence, focusing on a checklist of individual symptomology, an individual's "trauma narrative”, and individual assessment of deficiency continues to obliterate cultural agency. Further, requiring compliance to treatment as Western medicine prescribes, reverberates the dynamics of power and territorial control that originally sustained genocidal traumas. The South African Truth and Reconciliation Committee's final report states:

\footnotetext{
${ }^{6}$ From Feuerverger and Richards (2007, p. 557).
} 
International Journal of Child, Youth and Family Studies (2011) 3 \& 4: 432-449

Restorative justice seeks to repair the injustice and to effect corrective changes in the record, in relationships, and future behaviour. [New] South Africa ... is concerned not so much with punishment as with correcting imbalances, restoring broken relationships with healing, harmony, and reconciliation ... to empower individuals to take control of their own lives. (as cited in Short, 2005, p. 269)

The call often heard in the West, to "[afford] indigenous peoples equal recognition and respect ... . [and extend] universal fundamental political rights” (Short, 2005, p. 275), while theoretically genuine, is disenfranchising: It seems to locate the African (the Aboriginal, the subaltern brown woman) in a position that is "lower", with the act of "transfer" as one that is bestowed, a generous act and not a fundamentally restorative one. Further, the discourse of "rights" is also seen to be a Western notion; in indigenous or Eastern or African discourse I have noticed more discussion of "responsibilities". The constructs of "empowerment” and "[taking] control” are also very reflective of a particularly located thought - I would posit it's not grounded in indigeneity.

The "issue" at stake for Congolais(e) and Rwandais(e) war survivors is not simply a "moving on" from the past affected by war. It is a political affirmation of selfhood, a change in collective responsibility, and a global acknowledgment of legislated murder, legislated poverty, and legislated racism. In short, it is a call to witness to cultural, political, and symbolic change. Unless PTSD expands its current ideology of trauma, limited and potentially harmful treatment is a probable outcome. Current treatment simply lacks cultural relevance, contaminating instead the spirit of the self and its community. This lack of a Rwandan voice in treating a particular Rwandan injury perpetuates the era of a Rwandan with no social capital (McKenzie \& Harpham, 2006; Whitley \& McKenzie, 2005). While I wish to acknowledge that PTSD treatment is largely governed by people who work with genuine intent to alleviate mental distress not only from "horrible imaginings", but actual and lived "present fears", my main suggestion here is that even - or especially - so, there is need for pause in navigating future directions. There is need for a more considered (if not equitable) point of departure in trauma treatment. As Watters (2010) suggests, "perhaps it’s time that we rethink our generosity” (p. 255). 
International Journal of Child, Youth and Family Studies (2011) 3 \& 4: 432-449

\section{References}

American Psychiatric Association (APA). (1994). Diagnostic and statistical manual of mental disorders (DSM-IV), (4th ed. rev). Washington, DC: Author.

Bagilishya, C. (2000). Mourning and recovery from trauma: In Rwanda, tears flow within. Transcultural Psychiatry, 37(3), 337-353.

Beah, I. (2007). A long way gone: Memoirs of a boy soldier. Vancouver: Douglas-MacIntyre.

Bhugra, D., \& McKenzie, K. (2010). Expressed emotion across cultures. In R. Bhattacharya, S. Cross, \& D. Bhugra (Eds.), Clinical topics in cultural psychiatry (pp. 52-67). London: Royal College of Psychiatrists; England.

Bhui, K., McKenzie, K., \& Gill, P. (2004). Delivering mental health services for a diverse society. British Medical Journal, 329(7462), 363-364.

Blackwell, D. (2003). Colonialism and globalisation: A group-analytic perspective. Group Analysis, 36(4), 445-463.

Blackwell, D. (2005). Psychotherapy, politics, and trauma: Working with survivors of torture and organised violence. Group Analysis, 38(2), 307-323.

Bouchard, L., \& Leis, A. (2008). La santé en français. In J. Y. Thériault, A. Gilbert, \& L. Cardinal (Eds.), L'espace francophone en milieu minoritaire au Canada (pp. 351-387). Québec: Édition Fides.

Bourdieu, P., \& Wacquant, L. (1992). An invitation to reflexive sociology. (L. Wacquant, Trans.). Cambridge: Polity.

Bowlby, J. (1977). The making and breaking of affectional bonds. British Journal of Psychiatry, 130, 201-210.

Bracken, P. J., Giller, J. E., \& Summerfield, D. (1995). Psychological responses to war and atrocity: The limitations of current concepts. Social Science \& Medicine, 40(8), 1073-1082.

Canadian Broadcasting Corporation [CBC]. (2009, March 20). India reborn: Mother India [Television series, episode 4 of 4, Video/DVD]. Toronto: Author.

Canadian Centre for Victims of Torture. (2009, Winter). First light: Genocide, war crimes, and crimes against humanity. Toronto: Author.

Center on Law \& Globalization. (2011). Common ideologies foment and justify genocide.http://clg.portalxm.com/library/keytext.cfm?keytext_id=183 (last retrieved March 15, 2011). 
International Journal of Child, Youth and Family Studies (2011) 3 \& 4: 432-449

Dallaire, R. (2003). Shake hands with the devil: The failure of humanity in Rwanda. Toronto: Vintage.

Favila, I. Z., \& Fellow, L. (2009). Treatment of post-traumatic stress disorder in post-genocide Rwanda. Hanover, NH: Dartmouth College.

Feuerverger, G., \& Richards, E. (2007). Finding their way: Immigrant students in a Toronto school. In D. Thiessen \& A. Cook-Sather (Eds.), International handbook of student experience in elementary and secondary school (pp. 555-575). Hamburg: Springer.

Foucault, M. (1972). The archaeology of knowledge and the discourse of language. (M. A. Sheridan, Trans.). New York: Pantheon.

Foucault, M. (1979). The birth of biopolitics: Lectures at the collège de France. (G. Burchell, Trans.). New York: Picador.

Foucault, M. (1995). Discipline and punish: The birth of the prison.. New York: Vintage.

Foucault, M. (2003). The birth of the clinic. (A. M. Sheridan, Trans.). London: Routledge.

Grenfell, M. (2008). Bourdieu: Key concepts. Durham, UK: Acumen.

Humphrey, M. (2005). Reconciliation and the therapeutic state. Journal of Intercultural Studies, 26(3), 203-220.

Kupchan, C., \& Mount, A. (2009). The autonomy rule. Democracy: A Journal of Ideas, 12(Spring), 8-21.

Madan, A. (2010a). Comment: Is trauma counselling in foreign cultures a bad idea? Q blog (CBC radio one). Message posted to http://www.cbc.ca/q/blog/2010/02/08/is-traumacounselling-in-foreign-cultures-a-bad-idea-1/ (last retrieved December 21, 2010).

Madan, A. (2010b). Saisir les étoiles: Fostering a sense of belonging with child survivors of war. In P. Jones (Ed.), Drama as therapy, volume 2: Clinical work and research into practice (pp. 260-277). London: Routledge.

Madibbo, A. (2005, June). Immigration, race, and language: Black francophones of Ontario and the challenge of integration, racism, and language discrimination. Toronto: Joint Centre of Excellence for Research on Immigration and Settlement.

Mckenzie, K., \& Harpham, T. (Eds.). (2006). Social capital and mental health. London: Kingsley.

McKenzie, K., \& Harpham, T. (2006). Meanings and uses of social capital in the mental health field. In K. McKenzie \& T. Harpham (Eds.), Social capital and mental health (pp. 11-23). London: Jessica Kingsley Publishers. 
International Journal of Child, Youth and Family Studies (2011) 3 \& 4: 432-449

McLellan, J. (1995). Cambodian refugees in Ontario: An evalution of resettlement and adaptation. North York, ON: York Lanes Press.

Moncrieff, J. (2010). Psychiatric diagnosis as a political device. Social Theory \& Health, 8, 370382.

Moses, D. (2006). Why the discipline of "genocide studies" has trouble explaining how genocides end? Social Science Research Council: 22 December 2006.

Munshi, A., Woods, N., \& Hodges, B. (2010). Psychiatry, war, and the learning needs of residents. Acad Psychiatry, 34(3), 208-210.

Murray, C., \& and Lopez, A. (Eds.). (1996). The global burden of disease: A comprehensive assessment of mortality and disability from disease, injury, and risk factors in 1990 and projected to 2020. Cambridge, MA: Harvard School of Public Health.

National Institute of Mental Health [NIMH]. (2002). Mental health and mass violence: Evidence-based early psychosocial intervention for victims/survivors of mass violence: A workshop to reach consensus on best practices. Washington, DC: U.S. Government Printing Office.

Office of the Special Advisor on the Prevention of Genocide. (2011). Work of the office: Country situations. Geneva: UNCHR. Website access at http://www.un.org/en/preventgenocide/adviser/country_situations.shtml (last retrieved April 2011).

Revell, B. (2001). Jouons avec les arcs-en-ciel : Le program national de jeu pour des enfants à risque réfugiés. Ottawa: YWCA Press.

Seabrook, J. (2003). The no-nonsense guide to world poverty. Oxford: New Internationalist Publications Ltd.

Shamsuddin, A. K. (2009, February 25). Bureaucracy in Bangladesh [letter to the editor]. The Bangladesh Obsever, p. 5.

Short, D. (2005). Reconciliation and the problem of internal colonialism. Journal of Intercultural Studies, 26(3), 267-282.

Simich, L. (2010). Health literacy, immigrants and mental health. Canadian Issues / Thèmes Canadiens, Summer 2010, 17-22.

Snider, L., Cabrejos, C., Marquina, E. H., Trujillos, J. J., Avery, H., \& Aguilar, H. A. (2004). Psychosocial assessment for victims of violence in Peru: The importance of local participation. Journal of Biosocial Science, 36(4), 389-400. 
International Journal of Child, Youth and Family Studies (2011) 3 \& 4: 432-449

Summerfield, D. (1998). Protecting children from armed conflict. Children affected by war must not be stigmatised as permanently damaged. British Medical Journal, 317(7167), 1249.

Summerfield, D. (1999). A critique of seven assumptions behind psychological trauma programmes in war-affected areas. Social Science \& Medicine, 48(10), 1449-1462.

Summerfield, D. (2001a). Commentary: The impact of past trauma in later life. Psychiatric Bulletin, 25(11), 438.

Summerfield, D. (2001b). The invention of post-traumatic stress disorder and the social usefulness of a psychiatric category. British Medical Journal, 322(7278), 95-98.

Summerfield, D. (2008). How scientifically valid is the knowledge base of global mental health? British Medical Journal, 336(7651), 992-994.

Summerfield, D. (1995). Addressing human response to war and atrocity: Major challenges in research and practices and the limitations of western psychiatric models. In R. J. Kleber, C. R. Figley, \& B. P. R. Gersons (Eds.), Beyond Trauma (pp. 17-29). New York: Plenum.

United Nations. (2009). UNHCR statistical yearbook, 2009: Country data sheets. Geneva: UNHCR.

Text of the 1951 Convention on the Prevention and Punishment of the Crime of Genocide. (1948; enacted 1951). Geneva: UNHCR.

United Nations High Commissioner for Refugees. (2011). Asylum seekers: Asylum levels and trends in industrialized countries 2010. Geneva: UNHCR.

Vasilevska, B., Madan, A., \& Simich, L. (2010). Refugee mental health: Promising practices and partnership building resources for settlement workers. Toronto: Centre for Addiction and Mental Health.

Venne, M. (1997). La francophonie face à la mondialisation. Quelle Francophonie Pour Le XXIiè Siècle? (pp. 247-267). Paris: Karthala.

Watters, E. (2010). Crazy like us: The globalization of the American psyche.. New York: Free Press.

Whitley, R., \& McKenzie, K. (2005). Social capital and psychiatry: Review of the literature. Harvard Review of Psychiatry, 13(2), 71-84.

World Health Organization [WHO]. (2004). Promoting mental health: Concepts, emerging evidence, and practice: Summary report. Geneva: Author.

Yohani, S. (2010). Nurturing hope in refugee children during early years of post-war adjustment. Children and Youth Services Review, 32(6), 865-873. 